\title{
ALTERNATIVA PARA RECONSTRUÇÃO DA PAREDE ABDOMINAL
}

\author{
Carvalho, $\mathrm{EA}^{1}$ \\ Cesar, $\mathrm{RMM}^{1}$ \\ Soares, $\mathrm{PGON}^{2}$ \\ Salles $\mathrm{PO}^{3}$ \\ Cintra, $\mathrm{CA}^{4}$ \\ Moreira, $\mathrm{RCL}^{5}$ \\ Miyata, $S^{6}$
}

\footnotetext{
${ }^{1}$ Residentes de Cancerologia Cirúrgica do Instituto Mário Penna - Hospital Luxemburgo

${ }^{2}$ Residente de Clínica Médica do Hospital João XXIII

${ }^{3}$ Patologista do Instituto Mário Penna - Hospital Luxemburgo

${ }^{4}$ Cirurgião oncológico do Instituto Mário Penna - Hospital Luxemburgo

${ }^{5}$ Coordenadora da Cirurgia Oncológica do Instituto Mário Penna - Hospital Luxemburgo

${ }^{6}$ Coordenador da Residência de Cirurgia Oncológica do Instituto Mário Penna - Hospital Luxemburgo
}

Correspondência:

Erlon de Ávila Carvalho. Instituto Mário Penna- Hospital Luxemburgo Belo Horizonte- MG. E-mail: ehawilla@yahoo.com.br

Resumo: A parede abdominal representa a via de acesso para todos os procedimentos operatórios dentro da cavidade celômica e para a maioria dos procedimentos nas áreas retro peritoneais, conseqüentemente a incisão e sutura da parede abdominal é um dos mais comuns exercícios da prática cirúrgica. Freqüentemente os cirurgiões oncológicos encontram lesões extensas que necessitam grandes ressecções da parede abdominal e um desafio na reconstrução da mesma. Apresentamos um caso em que optamos pela utilização do útero como alternativa para fechamento da parede abdominal.

Palavras-chave: Parede abdominal, útero, reconstrução abdominal.

Abstract: The abdominal wall represents the gateway to surgical procedures within coelomic cavity and a important access to retroperitoneal areas, therefore it's incision and suture is one of the most common surgical practices. Oncology surgeons frequently find extensive lesions that demands large resections of the abdominal wall and rebuilding it can be a challenge. We present here a case in witch the uterus was used as an alternative to abdominal wall's reconstruction.

Key words: Abdominal wall, uterus, abdominal reconstruction.

\section{INTRODUÇÃO}

A parede abdominal representa a porta de entrada para todos os procedimentos operatórios dentro da cavidade celômica e para a maioria dos procedimentos nas áreas retroperitoneais ${ }^{1}$, conseqüentemente a incisão e sutura da parede abdominal é um dos mais comuns exercícios da prática cirúrgica ${ }^{1}$. 
O fechamento da parede abdominal é um procedimento de rotina e um dos primeiros atos ensinados ao cirurgião no inicio de sua carreira. A maneira como fazer geralmente reflete as tradições locais e as preferências pessoais de professores $^{1}$, sendo a seleção de materiais e técnicas mais comumente baseadas em tradições do que em ciência $^{1}$

Existem certos casos em que existe a necessidade de laparostomia e posterior fechamento $^{2,3}$. Freqüentemente os cirurgiões oncológicos encontram lesões extensas que necessitam grandes ressecções da parede abdominal e um desafio na reconstrução da mesma.

\section{OBJETIVOS}

Discutir uma alternativa eficaz de fechamento de parede abdominal sob a forma de apresentação de um relato de caso.

\section{MATERIAL E MÉTODOS}

Relato de Caso. SAO, 45anos, feminino, portadora de adenocarcinoma de cólon transverso com invasão macroscópica da parede abdominal (figura 1).
Tomografia Computadorizada (TC): ausência de metastáses hepáticas ou linfonodais e invasão da parede abdominal. Foi submetida em outro serviço a colostomia paliativa que não excluiu o trânsito intestinal. Após estadiamento oncológico adequado optamos por reintervenção cirúrgica. Feito hemicolectomia em bloco com parede abdominal infraumbilical, cistectomia parcial, reconstrução do trânsito intestinal e da parede abdominal com utilização do útero. Tracionamos o útero em direção à parede anterior, fixamos o ligamento úterosacro no oblíquo externo (figura 2). A bexiga ficou exposta na parede abdominal. Colocamos Bolsa de Bogotá para revestimento do útero que foi retirada no $5^{\circ}$ dia pós-operatório (DPO). Paciente recebeu alta no $7^{\circ}$ DPO com orientação para curativos domiciliares com Alginato no tecido de granulação formado. Laudo anatomopatológico

(LAP): Presença de adenocarcinoma colonico moderadamente diferenciado invadindo parede abdominal, com 8 linfonodos comprometidos com neoplasia em 36 dissecados. Estadiamento T4b N2b M0, estágio IIIC. Paciente encaminhada para Quimioterapia Adjuvante (QTX). Paciente encontra-se no $12^{\circ}$ mês de acompanhamento pós-operatório sem 
sinais de recidiva da doença ou herniação da parede abdominal (figura 3).

\section{DISCUSSÃO}

A reconstrução da parede abdominal em plano total abrange diversas técnicas objetivando restaurar a continência do compartimento intrabdominal e a integridade do envelope cutâneo. O uso de telas inorgânicas é uma opção quando a reconstrução com tecido autólogo não e possível. Seu uso indiscriminado pode ser um considerado um abuso. Apresentamos uma alternativa quando a utilização de retalhos ou de Telas Inorgânicas não for possível de ser realizada. Não encontramos relatos publicados na literatura em que se utilizou o útero com auxiliar para laparorrafia como no nosso caso descrito. $\mathrm{O}$ útero proporcionou um excelente fechamento da parede. $\mathrm{O}$ tecido de granulação desenvolvido, por ser autólogo, pode ajudar a evitar complicações freqüente do uso da tela: rejeição, fístulas gastrointestinais, infecções da parede, necrose do subcutâneo e sensação de corpo estranho.

\section{CONCLUSÃO}

O Cirurgião Oncológico precisa estar preparado para realizar grandes ressecções e reconstruções para realização de tratamento oncológico adequado. A invasão de órgãos ou parede abdominal não deve ser considerada critério de irressecabilidade até que seja corretamente estadiado clinicamente e cirurgicamente ${ }^{4}$.

Embora não tenha sido possível a avaliação do resultado do procedimento à longo prazo podemos afirmar o uso do útero apresenta-se como solução factível para desenvolvimento de um tecido de granulação e fechamento por segunda intenção da parede abdominal. 


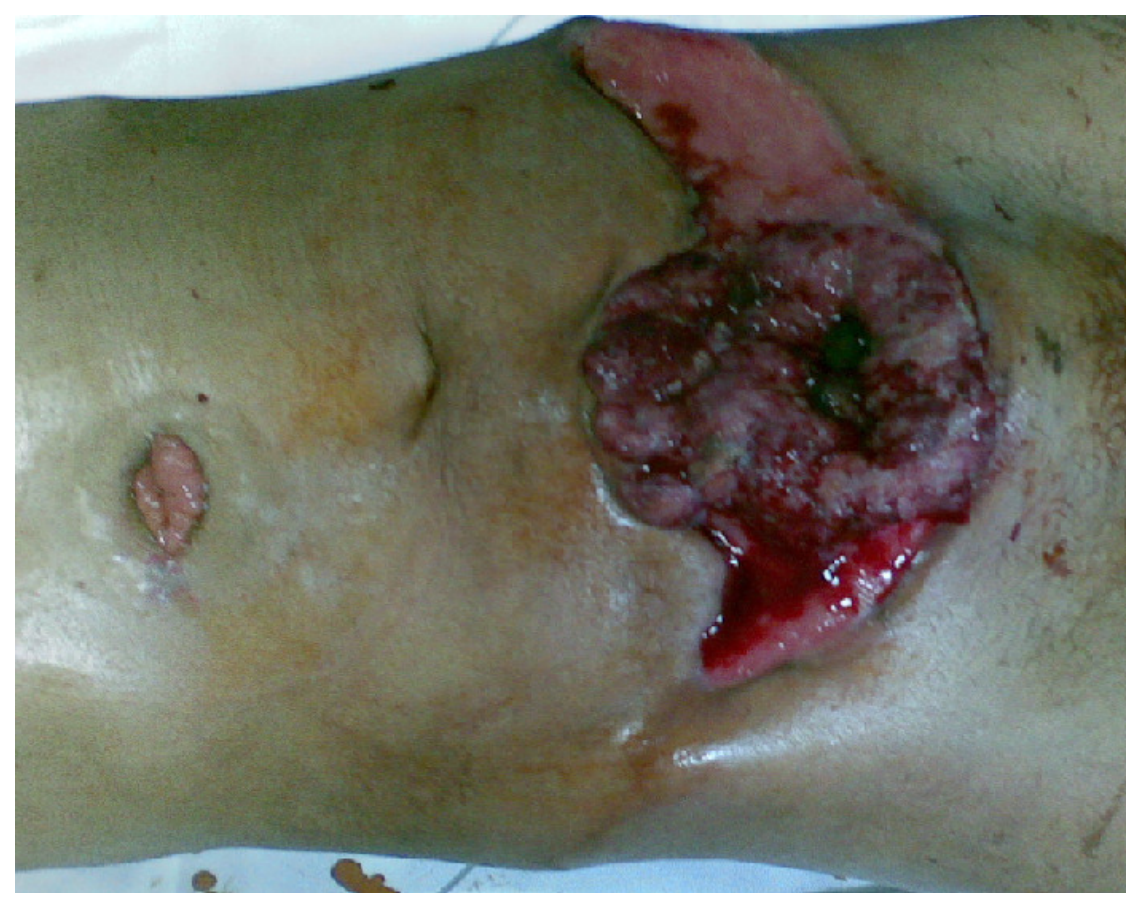

Figura 1: Fístula entero-cutânea devido à invasão da parede abdominal pelo tumor

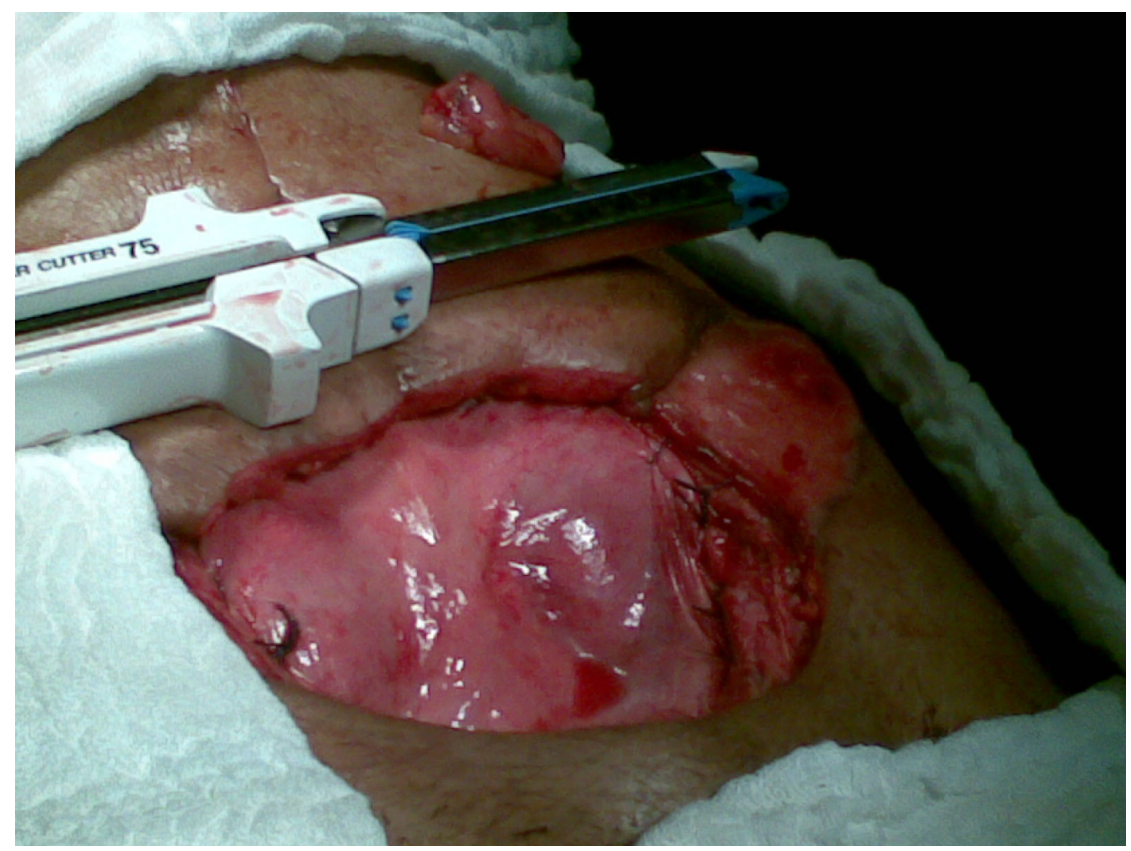

Figura 2: Utilização de útero para reconstrução da parede abdominal 


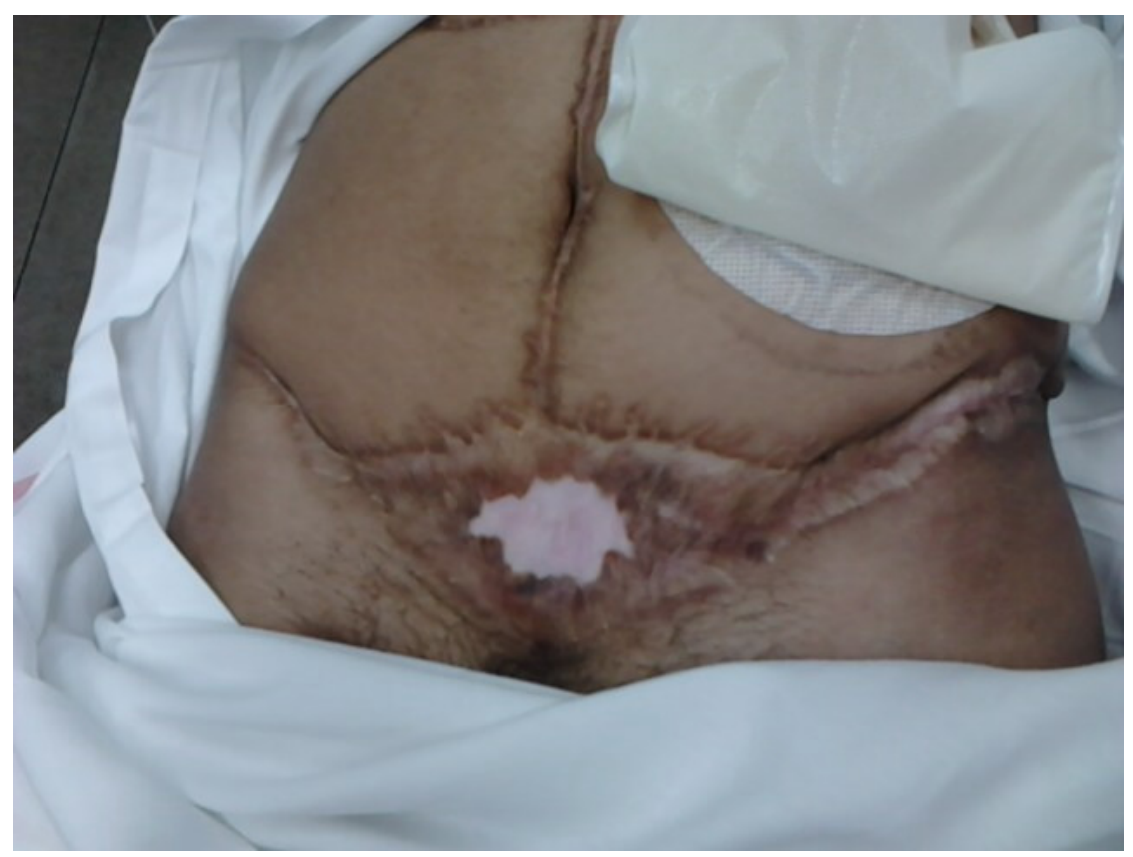

Figura 3: Aspecto de cicatrização após 1 ano de follow-up.

\section{REFERÊNCIAS}

1) TOGNINI, J. R. F.; GOLDENBERG,

S. Síntese da parede abdominal: sutura contínua ou com pontos separados?

Revisão da literatura. Acta Cirurgica Brasileira, São Paulo, v. 13, n.

2, Apr. 1998

2) FERRAZ, E. D.; VIEIRA, O. M. Técnica de fechamento progressivo na laparostomia e descompressão abdominal. Rev. Col. Bras. Cir., Rio de Janeiro, v. 27, n. 4, ago. 2000

3) REIS, M.C.W.; Melo, R.M.; Santana,D.P.; Almeida, C.T.; Lima, H.R.B.. Reconstrução abdominal tardia sem tensão após laparostomia: uma nova técnica. Rev. Col. Bras. Cir., Rio de Janeiro, v. 33, n. 3, jun. 2006

4) POSTON, G.J.; BEAUCHAMP, R.D.; RUERS, T.J.M. Textbook of Surgical Oncology. Reino Unido: Informa Healthcare, 2007. 429p. 